$\xi=-$ 国

\title{
Analysis of Physical Distribution of Sediment at Sembrong Reservoir Using GRADISTAT
}

\author{
SINS Hashim ${ }^{1 *}$, SHA TAlib ${ }^{2}$, MS Abustan ${ }^{3}$ \\ ${ }^{1,2,3}$ Faculty of Civil and Environmental Engineering, Universiti Tun Hussein Onn Malaysia, Parit Raja Batu Pahat, Johor \\ . Corresponding author E-mail: syarifahintannajla@ gmail.com
}

\begin{abstract}
Sembrong reservoir is a flood-control reservoir which is managed by Syarikat Air Johor since 1984. The reservoir provides clean water supply to 240,000 consumers in the district of Kluang and some parts of Batu Pahat. Reservoir storage is often affected by sedimentation due to soil erosion in the catchment area. As the sediments accumulate, the reservoir gradually loses its ability to store water for the purposes for which it was built. This research is initiated to characterize the sediment which could be used as control in future research in the treatment of contaminated sediment. The objective of this study was to determine the distribution of sediment at Sembrong Reservoir. In this experiment, sediment sampling was done using gravity corer at 6 different points throughout the reservoir. In addition, the physical properties of sediment is investigated by conducted experiments include scanning electron microscope (SEM) and particle size distribution The analysis of sediment distribution was done using GRADISTAT. Results obtained from the analysis shows that the particle in Sembrong reservoir were classified as very coarse sand and sandy gravel.
\end{abstract}

Keywords: GRADISTAT; Particle Size Distribution; Scanning Electron Miscroscope (SEM); Sediment.

\section{Introduction}

A reservoir is characterized by its particular sediment size and composition, although a large amount of variability may exist in the reservoir. Quantification of the grain size distribution of sediments allows interpretation of processes of transport and deposition [1]. Therefore, an investigation of spatial changes in grain size parameters (mean grain size, sorting and skewness) may allow for the identification of sediment properties at Sembrong reservoir.

Sediment is a major cause of various problems related care and management of the lakes or reservoirs. Sedimentation process will also lead to a shallower lakes and reservoirs and may continue to disappear. The implication would cause flash floods and flooding at the mouth of a drain. Too much sediment collected in lakes and rivers will result in shallow lakes and rivers. The effect during the rainy season, the area will be more susceptible to flooding. Measurements of sediment physical properties describe in various ways the density of sediment particles, their packing relations, and connections between particles [2]. While, according to Waddel [3], the interactions between the sediments and overlying water significantly affect the chemical and physical characteristics of lakes and reservoirs, also the processes governing those interactions are complex.

\section{Literature Review}

Particle-size distribution (PSD) is crucial to the classification and description of soils and sediments. Statistical correlation and regression models areused to compare the fractions of clay, silt and sand obtained with different methods.
Dry sieve analysis is carried out on particles coarser than $75 \mathrm{mi}-$ cron. Samples (with fines removed) are dried and shaken through a set of sieves of descending sizes. The weight retained in each sieve is measured. The cumulative percentage quantities finer than the sieve sizes (passing each given sieve size) are then determined [4]. The size distribution curves, as obtained from coarse and fine grained portions, can be combined to form one complete grainsize distribution curve (also known as grading curve).

GRADISTAT was inspired by Dave Thornley and John Jack at the Postgraduate Research Institute for Sedimentology at the University of Reading, UK, and the Department of Geology at Royal Holloway University of London, UK. It is provided in Microsoft Excel format to allow both spreadsheet and graphical output. The program is best suited to analyse data obtained from sieve or laser granulometer analysis. The user is required to input the mass or percentage of sediment retained on sieves spaced at any intervals, or the percentage of sediment detected in each bin of a Laser Granulometer. The following sample statistics are then calculated using the Method of Moments in Microsoft Visual Basic programming language: mean, mode(s), sorting (standard deviation), skewness, kurtosis, $\mathrm{D}_{10}, \mathrm{D}_{50}, \mathrm{D}_{90}, \mathrm{D}_{90} / \mathrm{D}_{10}, \mathrm{D}_{90}-\mathrm{D}_{10}, \mathrm{D}_{75} / \mathrm{D}_{25}$ and $\mathrm{D}_{75}-\mathrm{D}_{25}$.

Grain size parameters are calculated arithmetically and geometrically (in microns) and logarithmically (using the phi scale) [5]. Linear interpolation is also used to calculate statistical parameters by the Folk and Ward [6]. Graphical method and derive physical descriptions (such as "very coarse sand" and "moderately sorted"). The program also provides a physical description of the textural group which the sample belongs to and the sediment name (such as "fine gravelly coarse sand.

In terms of graphical output, the program provides graphs of the grain size distribution and cumulative distribution of the data in both metric and phi units, and displays the sample grain size on triangular diagrams. Samples may be analysed singularly, or up to 
250 samples may be analysed together. The program is ideal for the rapid analysis of sieve data.

\section{Materials and Methods}

Figure 1 shows the sampling location according to coordinates stated in Table 1. The locations were divided into three zones where each zone has two sampling points.

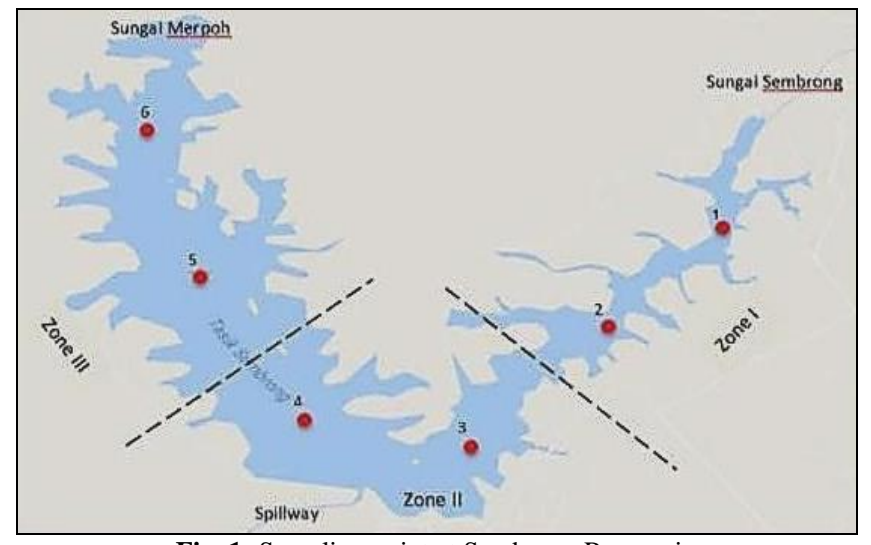

Fig. 1: Sampling point at Sembrong Reservoir

Table 1: Description of each zone at Sembrong Reservoir

\begin{tabular}{|c|c|c|c|}
\hline Zone & Station & $\begin{array}{c}\begin{array}{c}\text { Coordinates of } \\
\text { sampling location }\end{array} \\
\end{array}$ & Description of station \\
\hline \multirow[b]{2}{*}{ Zone I } & 1 & $\begin{array}{l}\text { N } 01^{\circ} 59^{\prime} 50.4^{\prime \prime} \\
\text { E } 103^{\circ} 12^{\prime} 08.0^{\prime \prime}\end{array}$ & \multirow{2}{*}{$\begin{array}{l}\text { This station is located near } \\
\text { to the inlet of Sungai Sem- } \\
\text { brong. The stations are } \\
\text { surrounded by farming and } \\
\text { agricultural activities. }\end{array}$} \\
\hline & 2 & $\begin{array}{l}\mathrm{N} 01^{\circ} 59^{\prime} 24.4^{\prime \prime} \\
\mathrm{E} 103^{\circ} 11^{\prime} 45.6^{\prime \prime}\end{array}$ & \\
\hline \multirow[b]{2}{*}{$\begin{array}{c}\text { Zone } \\
\text { II }\end{array}$} & 3 & $\begin{array}{l}\mathrm{N} 01^{\circ} 58^{\prime} 49.2^{\prime \prime} \\
\mathrm{E} 103^{\circ} 11^{\prime} 19.4^{\prime \prime}\end{array}$ & \multirow[t]{2}{*}{$\begin{array}{l}\text { This station is located near } \\
\text { to the spillway of reservoir. }\end{array}$} \\
\hline & 4 & $\begin{array}{l}\mathrm{N} 01^{\circ} 59^{\prime} 03.5^{\prime \prime} \\
\mathrm{E} 103^{\circ} 10^{\prime} 44.7^{\prime \prime}\end{array}$ & \\
\hline \multirow{2}{*}{$\begin{array}{l}\text { Zone } \\
\text { III }\end{array}$} & 5 & $\begin{array}{l}\mathrm{N} 01^{\circ} 59^{\prime} 38.6^{\prime \prime} \\
\text { E } 103^{\circ} 10^{\prime} 26.0^{\prime \prime}\end{array}$ & \multirow{2}{*}{$\begin{array}{c}\text { This station is located near } \\
\text { to the inlet of Sungai } \\
\text { Merpoh. There are many } \\
\text { stump, dead trees and oil } \\
\text { palm at this area. }\end{array}$} \\
\hline & 6 & $\begin{array}{l}\mathrm{N} 02^{\circ} 00^{\prime} 34.8^{\prime \prime} \\
\mathrm{E} 103^{\circ} 10^{\prime} 01.4^{\prime \prime}\end{array}$ & \\
\hline
\end{tabular}

Experiments began with sediment sampling at 6 different points in Sembrong reservoir. The average depth of Sembrong reservoir is between $2-5 \mathrm{~m}$. Standard core were used to collect the sediment samples. Figure 2 shows the sampling activities to collect the samples.

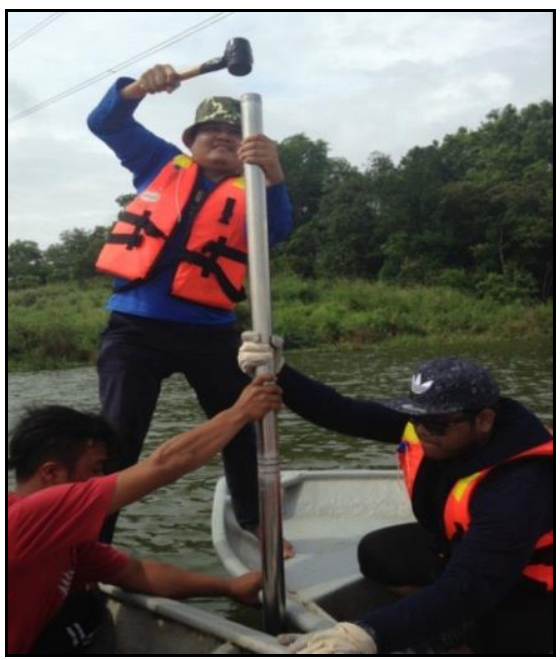

Fig. 2: The gravity corer used to get the sediment
From the water surface, a weight was dropped and hammered to the steel casing. The corer was hammered into the sediment as deep as possible until it reached the bottom depth of reservoir. Once the corer were lifted, the tube was immediately taken out from its casing and a cork was placed at the bottom of the tube to avoid the sediment from moving out. The tube was then vertically placed in a polystyrene box to keep its temperature before transferred to laboratory freezer with $4^{\circ} \mathrm{C}$.

Sieve analysis was done to measure the particle size distribution of sediment samples. In order to perform the test, a sufficient sample of the aggregate must be obtained from the sediment. To prepare the sample, the aggregate were mixed thoroughly and sieve using the shaker in Highway Laboratory, UTHM.

\subsection{Particle size distribution}

A computer program called GRADISTAT was applied for the rapid analysis of grain size statistics from any of the standard measuring techniques, such as sieving. Mean, mode, sorting, skewness and other statistics are calculated arithmetically and geometrically (in metric units) and logarithmically (in phi units) using moment and Folk and Ward graphical methods. The program runs within the Microsoft Excel spreadsheet package, accepting standard and non-standard size data, and producing a range of graphical outputs including frequency and plots.

The mean grain size refers to the average grain phi $(\phi)$ size of the sample. The Udden-Wentworth mean grain scale was used to classify the different classes of phi scale ranging from boulder to silt as shown in Figure 3.

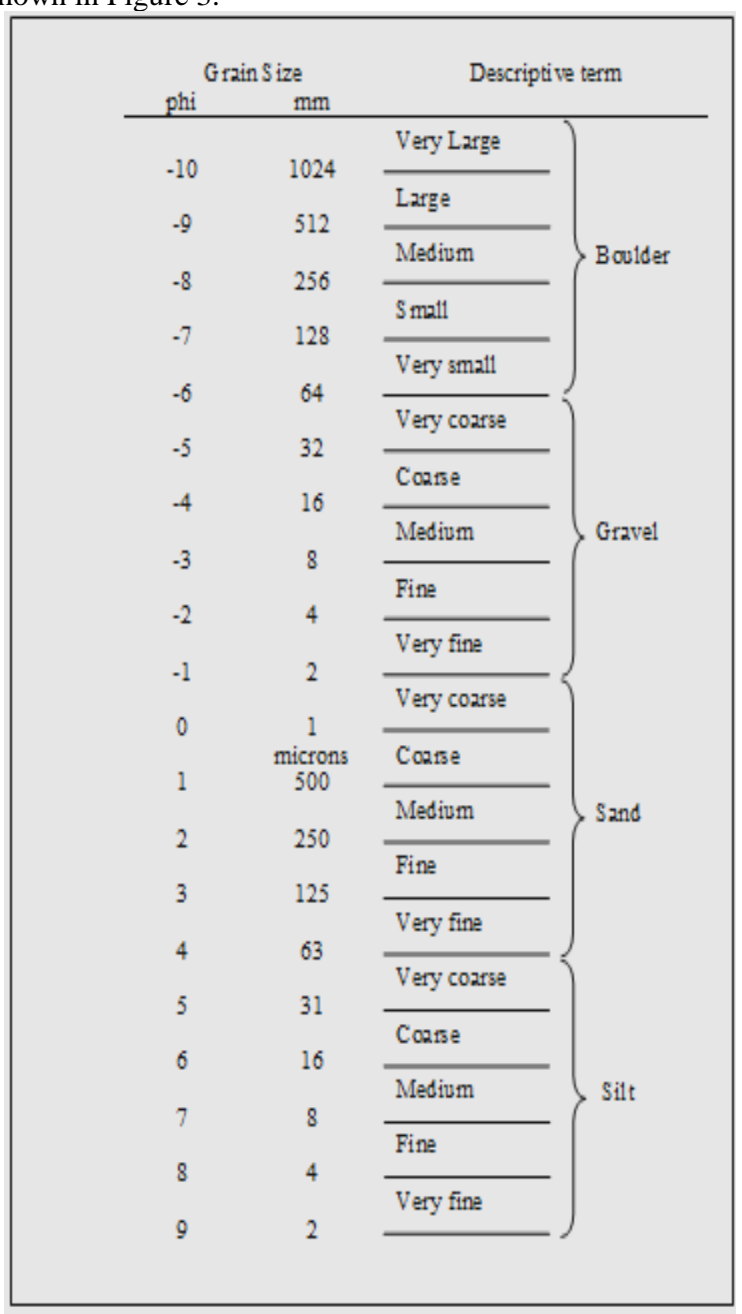

Fig. 3: Udden-Wentworth Grain Size Scale Classification [6].

Samples containing a wide range of sediment sizes have a large standard deviation and are poorly sorted. Samples with a small grain size range have a small standard deviation, hence are well 
sorted. Sorting and mean grain sizes were the two sediment characteristics analyzed in this modeling endeavor. The sorting classes are shown in Table 2 .

Table 2: Sorting Classification of Soil and Sediment [7]

\begin{tabular}{|c|c|}
\hline Sorting Range $(\varphi)$ & Description of Sorting \\
\hline $\mathbf{C 0 . 3 5}$ & Very well sorted \\
\hline $\mathbf{0 . 3 5}-\mathbf{0 . 5 0}$ & Well sorted \\
\hline $\mathbf{0 . 5 0}-\mathbf{0 . 7 1}$ & Moderately well sorted \\
\hline $\mathbf{0 . 7 1}-\mathbf{1 . 0 0}$ & Moderately sorted \\
\hline $\mathbf{1 . 0 0}-\mathbf{2 . 0 0}$ & Poorly sorted \\
\hline $\mathbf{2 . 0 0}-\mathbf{4 . 0 0}$ & Very poorly sorted \\
\hline$>\mathbf{4 . 0 0}$ & Extremely poorly sorted \\
\hline
\end{tabular}

Samples were analyzed in terms of skewness and kurtosis. Skewness is a measure of symmetry in the distribution curve. Sample with a negative skewness value contains coarser particle content Samples with positive skewness value contain more fine particulate matter. Classifications of skewness value are shown in Table 3.

Table 3: Skewness Classification of Soil and Sediment [7]

\begin{tabular}{|c|c|}
\hline Skewness Range $(\varphi)$ & Description of Skewness \\
\hline$<+\mathbf{0 . 3}$ & Very fine skewed \\
\hline $\mathbf{+ 0 . 3}$ to $\boldsymbol{+ 0 . 1}$ & Fine skewed \\
\hline $\boldsymbol{+ 0 . 1}$ to $-\mathbf{0 . 1}$ & Near Symmetrical \\
\hline $\boldsymbol{- 0 . 1}$ to $-\mathbf{0 . 3}$ & Coarse skewed \\
\hline$>\boldsymbol{- 0 . 3}$ & Very coarse skewed \\
\hline
\end{tabular}

Kurtosis distribution is the peak in the distribution curve. A sample is called leptokurtic if the centre is organized better than the tail. This means that the overall sizes of the particles are arranged in a very similar range. If the tail is sorted better than the middle part, it is called platykurtic. A Platykurtic curve shows that one of the particle size is more dominant compared to others. Classifications of kurtosis value are shown in Table 4.

Table 4: Kurtosis Classification of Soil and Sediment [7]

\begin{tabular}{|c|c|}
\hline Kurtosis Range $(\varphi)$ & Description of Kurtosis \\
\hline$<\mathbf{0 . 6 7}$ & Very platykurtic \\
\hline $\mathbf{0 . 6 7}-\mathbf{0 . 9 0}$ & Platykurtic \\
\hline $\mathbf{0 . 9 0}-\mathbf{1 . 1 1}$ & Mesokurtic \\
\hline $\mathbf{1 . 1 1}-\mathbf{1 . 5 0}$ & Leptokurtic \\
\hline $\mathbf{1 . 5 0}-\mathbf{3 . 0 0}$ & Very leptokurtic \\
\hline$>\mathbf{3 . 0 0}$ & Extremely leptokurtic \\
\hline
\end{tabular}

\section{Results and Discussion}

The data obtained from the experiments was analyses to obtain the results desired by the objectives of this research. The data were analyses in the form of graph and tables to give more understanding on the results of the experiment.

\subsection{Scanning Electron Microscope (SEM) of Sediment in Sembrong Reservoir}

Scanning Electron Microscope (SEM) testing captured the image according to the depth of 6 different locations to describe the particle shape. Figure 3 shows the image of particle shape captured using SEM.

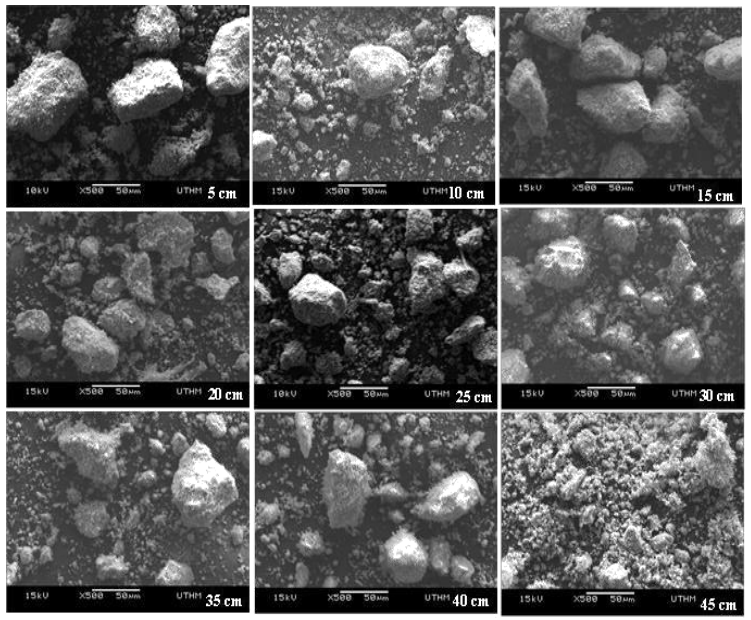

Fig. 4: Scanning Electron Microscope between 0-45 $\mathrm{cm}$ depths for Zone II (Location 3).

Figure 4 shows shape of particles of sediment, it can be seen that the shape is more to bulky and flaky categories. Bulky particles can be described into angular, sub angular, sub rounded and rounded shapes and it is clearly shown from their subfigure angular, sub rounded shape and also flaky particles. Besides that, it can be seen that the voids ratio is getting smaller as depth is deepens. Referring to [8], bulky particles are formed mostly by mechanical weathering of rock and mineral, while flaky particles have very usually 0.01 or less, these flaky particles are predominantly as clay minerals. It also stated that the shape of granular particles in a soil mass has a great influence on the physical properties of the soil, such as maximum and minimum void ratios, shear strength parameters and compressibility.

\subsection{Particle Size Distribution using GRADISTAT}

Based on the statistical (mean, sorting and skewness) values, the sediment distribution can be related to the spatial variations. In the interpretation of the data, the samples were grouped by their location as an initial step. The results of the grain size distribution analyses on 6sediment samples are given in Table 5 .

Table 5: Summary of particle size distribution in Sembrong Reservoir

\begin{tabular}{|c|c|c|c|c|c|c|}
\hline Point & Mean $(\mathrm{mm})$ & Mean $(\varphi)$ & Sorting & Skewness & Kurtosis & Type of Particle \\
\hline 1 & 0.09 & 1.07 & Poorly sorted & Fine skewed & Very Platykurtic & Sandy gravel \\
\hline 2 & 0.16 & 1.12 & Poorly sorted & Fine skewed & Platykurtic & Sandy gravel \\
\hline 3 & 0.16 & 1.12 & Poorly sorted & Fine skewed & Platykurtic & Sandy gravel \\
\hline 4 & 0.01 & 1.00 & Poorly sorted & Fine skewed & Platykurtic & Sandy gravel \\
\hline 5 & 0.30 & 1.23 & Poorly sorted & Fine skewed & Platykurtic & Sandy gravel \\
\hline 6 & 0.11 & 1.08 & Poorly sorted & Fine skewed & Platykurtic & Sandy gravel \\
\hline
\end{tabular}

The mean size value for the reservoir area ranged between $0.01 \mathrm{~mm}$ and $0.30 \mathrm{~mm}(1.00$ and $1.23 \phi)$, and the average value was $0.14 \mathrm{~mm}(1.13 \phi)$. It is noted that the highest mean size value is obtained from point 5 followed by point 2 and 3 as the second highest, whereas point 4 indicates the lowest mean size value. The mean diameter shows that the sediment in the reservoir's system consisted of coarse, medium, fine and very fine gravel as well as coarse, medium and fine sand. All sediments are classified as very coarse sand and sandy gravel.

Sediments in the reservoir area are poorly sorted sediment (1.0 to $2.0 \phi$ ). Poorly sorted indicates that the sediment sizes are mixed and particle settles within these points. The lowest value is found at point $4(1.01 \phi)$, while the highest value occurs at point 5 (1.33 $\phi)$. The results show that there are no significant changes among the points where only poorly sorted sediment types are found. 
Skewness is used to indicate whether the sediment consisted of an excess of fine or coarse fractions. The trends of skewness at Sembrong reservoir are between $0.24 \phi$ and $0.29 \phi$. These fine skewed which consists of positive values indicate that the grain-size distribution is influenced by fineparticles which is fine sand.

Kurtosis shows the sharpness of the peak of a frequencydistribution curve. The results show that the graph is in platykurtic curve with uniform distribution of sediment.

\section{Conclusion}

Textural analyses of reservoir sediment was undertaken to identify the grain size distributions and deposition at Sembrong reservoir. There were two types of sediment found in Sembrong reservoir. In the reservoir area, the inlet area was dominated by coarser sediment while finer sediment accumulated at the intake/spillway. The mean diameter showed that the sediment in the reservoir's system consisted of coarse, medium and fine gravel and sand according to Udden-Wenworth's classification, with the sand covered more than $80 \%$ of the sampling area.

The sediments across the reservoir consisted of poorly sorted sediments. This trend was shown by current refraction, caused by increased area size from a channel to a wide reservoir area. The highest concentrations of phosphorus and sediment occurred at the spillway which was dominated by fine particles. As a result, finer sediments will be transported to the downstream.

\section{Acknowledgement}

We thank Batu Pahat Department of Irrigation and Drainage for their hospitality, Universiti Tun Hussein onn and Ministry of Higher Education for funding this project under the Research Grant FRGS vot no. 1572 and Research, Innovation, Commercialization, Consultancy Office UTHM (ORICC) for Postgraduate Research Grant (GPPS) vot no. U934 and U785.

\section{References}

[1] Jutzeler M, McPhie J, Allen SR \& Proussevitch AA (2015), Grainsize distribution of volcaniclastic rocks 2: characterizing grain size and hydraulic sorting. Journal of Volcanology and Geothermal Research 301, 191-203.

[2] Herbert TD (1997), Life Cycle(S) of Sediment Physical Properties, Ceara Rise. German: D-24148 Kiel, Federal Republic.

[3] Waddell KM, Darby DW \& Theobald SM (1986) Chemical and Physical Characteristics of Water and Sediment in Scofield Reservoir, Carbon County, Utah. U.S. Burea of Land Management.

[4] Tickell FG (2011), The techniques of sedimentary mineralogy. Elsevier.

[5] Krumbein WC \& Pettijohn FJ, Manual of Sedimentary Petrography. Appleton-Century-Crofts, New York, (1938).

[6] Folk RL \& Ward WC (1957), Brazos River bar: a study in the significance of grain size parameters. Journal of Sedimentary Petrology 27, 3-26.

[7] Larson R, Morang A \& Gorman L (1997), Monitoring the coastal environment; part II: sediment sampling and geotechnical methods. Journal of coastal research, 308-330.

[8] Das BM (2010). Principles of Geotechnical Engineering. Adapted International Student Edition. Thomson. 